\title{
Penggunaan Web Crawler Untuk Menghimpun Tweets dengan Metode Pre-Processing Text Mining
}

\author{
Bayu Rima Aditya \\ Program Studi Manajemen Informatika, Fakultas Ilmu Terapan, Universitas Telkom \\ Jl Telekomunikasi No 1, Terusan Buah Batu Bandung \\ bayu@tass.telkomuniversity.ac.id
}

\begin{abstract}
Abstrak - Saat ini jumlah data di media sosial sudah terbilang sangat besar, namun jumlah data tersebut masih belum banyak dimanfaatkan atau diolah untuk menjadi sesuatu yang bernilai guna, salah satunya adalah tweets pada media sosial twitter. Paper ini menguraikan hasil penggunaan engine web crawel menggunakan metode pre-processing text mining. Penggunaan engine web crawel itu sendiri bertujuan untuk menghimpun tweets melalui API twitter sebagai data teks tidak terstruktur yang kemudian direpresentasikan kembali kedalam bentuk web. Sedangkan penggunaan metode pre-processing bertujuan untuk menyaring tweets melalui tiga tahap, yaitu cleansing, case folding, dan parsing. Aplikasi yang dirancang pada penelitian ini menggunakan metode pengembangan perangkat lunak yaitu model waterfall dan diimplementasikan dengan bahasa pemrograman PHP. Sedangkan untuk pengujiannya menggunakan black box testing untuk memeriksa apakah hasil perancangan sudah dapat berjalan sesuai dengan harapan atau belum. Hasil dari penelitian ini adalah berupa aplikasi yang dapat mengubah tweets yang telah dihimpun menjadi data yang siap diolah lebih lanjut sesuai dengan kebutuhan user berdasarkan kata kunci dan tanggal pencarian. Hal ini dilakukan karena dari beberapa penelitian terkait terlihat bahwa data pada media sosial khususnya twitter saat ini menjadi tujuan perusahaan atau instansi untuk memahami opini masyarakat.
\end{abstract}

Kata kunci - API twitter; cleansing, case folding, parsing, waterfall, black box testing.

Abstract - Amount of data the exponential growth we have seen in social-media, but it is not widely used to be something of value, one of which is tweets on twitter. This paper describes the result of using engine web crawler with pre-processing text mining method. The use of engine web crawler aims to take tweets via API Twitter as unstructured text data and then represented into web form. The use of pre-processing method aims to filter out tweets on three stages: cleansing, case folding and parsing. Applications designed in this research using the waterfall model and implemented with PHP. Testing method in this research using the black box testing to check whether the design result can already be run in accordance between expectations or not. Result from this research are in the form of applications that can help prepare tweets into data that can be processed according to needs based on keywords and the search date desire by the user. This is done because of several related research shown that data on social media, especially Twitter is currently the destination company or agency to understand public opinion.

Keywords - API twitter; cleansing, case folding, parsing, waterfall, black box testing

\section{PENDAHULUAN}

Analisis terhadap media sosial adalah alat yang ampuh untuk memahami sikap, preferensi dan opini masyarakat. Bagi suatu perusahaan, analisis media sosial dapat membantu perusahaan untuk membuat keputusan mengenai kebutuhan, sikap, pendapat atau trend tentang pelanggan atau calon pelanggan potensial. Tidak dapat dipungkiri, saat ini jumlah data di media sosial sudah terbilang sangat besar, namun jumlah data tersebut masih belum banyak dimanfaatkan atau diolah untuk menjadi sesuatu yang bernilai guna, salah satunya adalah pada salah satu media sosial terbesar di dunia yaitu twitter. Twitter menyediakan Application Program Interface (API) yang memungkinkan kita mendapatkan data mereka. Data yang dapat dimanfaatkan dari media sosial twitter itu sendiri adalah berupa status atau yang lebih dikenal dengan tweets.

Untuk mengubah tweets menjadi sebuah data yang memilki makna, maka diperlukan paling tidak dua proses awal, yaitu proses pengambilan tweets dari API Twitter dan proses penyaringan tweets agar dapat diolah menjadi data yang memiliki makna. Proses pengambilan tweets dari API twitter dapat dilakukan dengan menggunakan engine web crawel yang dapat merepresentasikan kembali data kedalam bentuk web. Untuk proses penyaringan tweets dapat menggunakan metode pre-processing text mining yang terdiri dari tiga tahap, yaitu cleansing, case folding, dan parsing. Untuk itu, dibutuhkan suatu aplikasi yang dapat membantu menghimpun data tweets dan membantu mempersiapkan data untuk diolah menjadi informasi. 
Paper ini menguraikan hasil penggunaan web crawel dalam menghimpun tweets dengan metode pre-processing text mining. Pembuatan web crawel bertujuan untuk mengambil tweets melalui API twitter sebagai data teks yang tidak terstruktur. Sedangkan penggunaan metode pre-processing bertujuan untuk mempersiapkan data teks menjadi data yang dapat diolah lebih lanjut atau sesuai kebutuhan user. Untuk pengujian dari aplikasi pada penelitian ini menggunakan black box testing untuk memeriksa apakah aplikasi sudah dapat berjalan sesuai dengan harapan atau belum.

Kontribusi yang diberikan penelitian ini adalah membantu mempersiapkan tweets menjadi data yang dapat diolah lebih lanjut sesuai dengan kebutuhan. Hal ini dilakukan karena dari beberapa penelitian terkait terlihat bahwa data pada media sosial khususnya twitter saat ini menjadi tujuan perusahaan atau instansi untuk memahami opini masyarakat.

Pembahasan dalam paper ini akan mengikut alur sebagai berikut. Di bagian II diuraikan metode penelitian termasuk di dalamnya uraian mengenai penelitian-penelitian lain yang sudah dilakukan terkait web crawler dan twitter. Selanjutnya dibagian III, diuraikan hasil pengujian dan pembahasan. Kesimpulan dari penelitian ini akan diuraikan di bagian IV.

\section{METODOLOGI PENELITIAN}

\section{A. Metode Penelitian}

Metode-metode yang digunakan dalam penelitian ini adalah sebagai berikut.

1. Studi pustaka, yaitu dilakukan dengan cara membaca berbagai referensi buku, literature, dan bacaan lainnya yang berhubungan dengan permasalahan yang sedang diteliti.

2. Metodologi pengembangan sistem yang digunakan pada penelitian ini adalah linear sequential model [7] seperti terlihat pada Gambar 1.

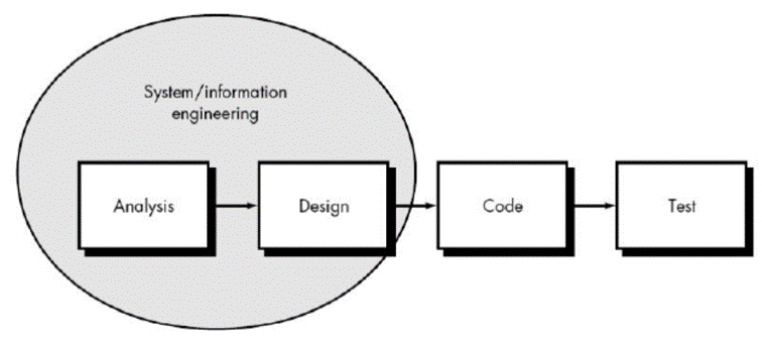

Gambar 1. Model Sekuensial Linier [6]

Model ini menyarankan pendekatan pengembangan secara sekuen dan sistematik untuk pengembangan sistem [7]. Adapun perangkat keras dan perangkat lunak yang dibutuhkan oleh dalam pengembangan sistem ini adalah seperti terlihat pada Tabel 1 dan Tabel 2.

Tabel 1. Kebutuhan Perangkat Keras

\begin{tabular}{cll}
\hline No & Perangkat Keras & \multicolumn{1}{c}{ Spesifikasi } \\
\hline 1 & Processor & Intel Core i3 \\
2 & RAM & $2 \mathrm{~GB}$ \\
3 & Harddisk & $500 \mathrm{~GB}$ \\
\hline
\end{tabular}

\begin{tabular}{clll}
\multicolumn{4}{c}{ Tabel 2. Kebutuhan Perangkat Lunak } \\
\hline No & \multicolumn{2}{c}{ Perangkat Lunak } & \multicolumn{1}{c}{ Spesifikasi } \\
\hline 1 & $\begin{array}{l}\text { Web browser } \\
\text { debugging tool }\end{array}$ & Google Chrome \\
& & Macromedia \\
2 & Script Editor & Dreamweaver \\
& & CS5 \\
\hline
\end{tabular}

3. Metode yang digunakan dalam proses penghimpunan tweets pada penelitian ini adalah preprocessing text mining. Tahapan yang dilakukan dari proses pre-processing text mining itu sendiri adalah sebagai berikut [5].

a. Cleansing, yaitu proses membersihkan tweets dari kata yang tidak diperlukan untuk mengurangi noise. Kata yang dihilangkan adalah karakter HTML, kata kunci, ikon emosi, hashtag (\#), username (@username), url (http://situs.com), dan email (nama@situs.com).

b. Case folding, yaitu mengubah semua huruf menjadi lowercase atau huruf kecil.

c. Parsing, yaitu proses memecah tweets menjadi sebuah kata. Hal ini sesuai dengan fitur digunakan yaitu unigram.

\section{B. Penelitian Terkait}

1. Dewi Rosmala dan Rizkqi Rivani Syafei dalam penelitiannya berjudul "implementasi web crawler pada social media monitoring" menyimpulkan hasil penelitiannya bahwa, implementasi web crawler pada aplikasi social media monitoring dapat memudahkan user memantau issue-issue yang sedang terjadi terhadap sebuah brand image dari sebuah produk. Dengan adanya aplikasi ini diharapkan mampu membantu pengguna juga untuk menjada brand image. Dan jika dikembangkan aplikasi ini tidak hanya dapat memantau saja, melainkan diharapkan dapat menjadi sumber key learning bagaimana menciptakan strategi promosi yang sukses [8].

2. Yohanes Sigit, dkk dalam penelitiannya berjudul Analisis dan Perancangan Alat Bantu Monitor Brand Universitas Atma Jaya Yogyakarta di Situs Jejaring Sosial Twitter menyimpulkan bahwa untuk menganalisis brand monitoring universitas atma jaya Yogyakarta dapat dilakukan dengan 
menggunakan sebuah perangkat lunak sebagai alat bantu untuk mengcapture data-data dari situs jejaring social twitter. Dan jika dikembangkan lebih lanjut, alat bantu ini dapat bermanfaat untuk mengetahui bagaimana pendapat masyaratak (pengguna twitter) mengenai brand Universitas Atma Jaya Yogyakarta untuk melakukan pengembangan Universitas menjadi lebih baik [9].

3. Pipit Pitria dalam penelitiannya berjudul Analisis Sentimen Pengguna Twitter Pada Akun Resmi Samsung Indonesia Dengan Menggunakan Naive Bayes menyimpulkan hasil penelitiannya bahwa pemanfaatan analisis sentimen biasanya digunakan untuk mengevaluasi sebuah produk yang sentimensentimennya didapat dari feedback sebuah produk itu sendiri melalui social media khususnya twitter. Studi kasus yang digunakan dalam penelitian ini sebagai uji coba implementasi adalah akun twitter resmi Samsung Indonesia yang aktif dalam mempromosikan produk-produknya [6].

\section{Tinjauan Pustaka}

\section{Preprocessing Text Mining}

Menurut definisi, Text Mining adalah proses menambang data yang berupa teks dimana sumber data biasanya didapatkan dari dokumen dan tujuannya adalah mencari katakata yang dapat mewakili isi dari dokumen sehingga dapat dilakukan analisis keterhubungan antar dokumen tersebut [1]. Text mining mengekstrak informasi berguna dari sumber data melalui identifikasi dan eksplorasi yang tidak dalam bentuk database record, melainkan dalam data teks yang tidak terstruktur. Preprocessing adalah tahap proses awal text mining terhadap teks untuk mempersiapkan teks menjadi data yang dapat diolah lebih lanjut. Sekumpulan karakter yang bersambungan (teks) harus dipecah-pecah menjadi unsur yang lebih berarti. Suatu dokumen dapat dipecah menjadi bab, sub-bab, paragraf, kalimat, kata dan bahkan suku kata [3].

2. Status Twitter (tweets)

Tweets adalah pesan yang ditulis oleh pengguna media sosial twitter. Tweets itu sendiri berupa teks tulisan yang dapat memuat hingga 140 karakter yang ditampilkan pada halaman profil user [10].

3. Web Crawler

Web crawler adalah sebuah perangkat lunak yang diguankan untuk menjelajah serta mengumpulkan halaman-halaman web yang selanjutnya diindeks oleh mesin pencari [4]. Sedangkan proses crawling adalah proses yang digunakan oleh mesin pencari (search engine) untuk mengumpulkan halaman website [2].

\section{HASIL DAN PEMBAHASAN PENELITIAN}

\section{A. Analisis Sistem}

1. Analisis Sistem Berjalan

Masyarakat Indosnesia sudah tidak asing lagi dengan fenomena penggunaan twitter sebagai media untuk mengungkapkan ide, komentar, opini atau pernyataan terhadap suatu hal. Setiap saat orang-orang menuliskan apa yang ada dalam pikirannya untuk kemudian dishare ke twitter. Selain itu orang-orang pun dapat mengomentari tweet yang ditulis orang lain. Akan tetapi tweets yang ada saat ini hanya berupa tweets biasa dan belum banyak dihimpun untuk dijadikan suatu data atau informasi.

2. Sistem yang diusulkan

Dari permasalahan diatas, diperlukan sebuah solusi yaitu dengan mengumpulkan tweets dari API twitter. Sistem akan melakukan proses pencarian tweets berdasarkan kebutuhan yang kemudian diproses melalui metode preprocessing text mining. Hasilny akan direpresentasikan dalam bentuk sebuah web.

\section{B. Proses Penelusuran Tweets}

Proses penelusuran tweets merupakan proses yang perlu dilakukan untuk mengubah tweets menjadi sebuah data yang memiliki makna. Proses penelusuruan tweets dilakukan dengan cara pengambilan tweets dari API Twitter, kemudian dilakukan proses penyaringan tweets agar dapat diolah menjadi data yang memiliki makna. Proses penelusuran tweets yang diusulkan pada penelitian ini secara lebih detail dapat dilihat pada Gambar 2.

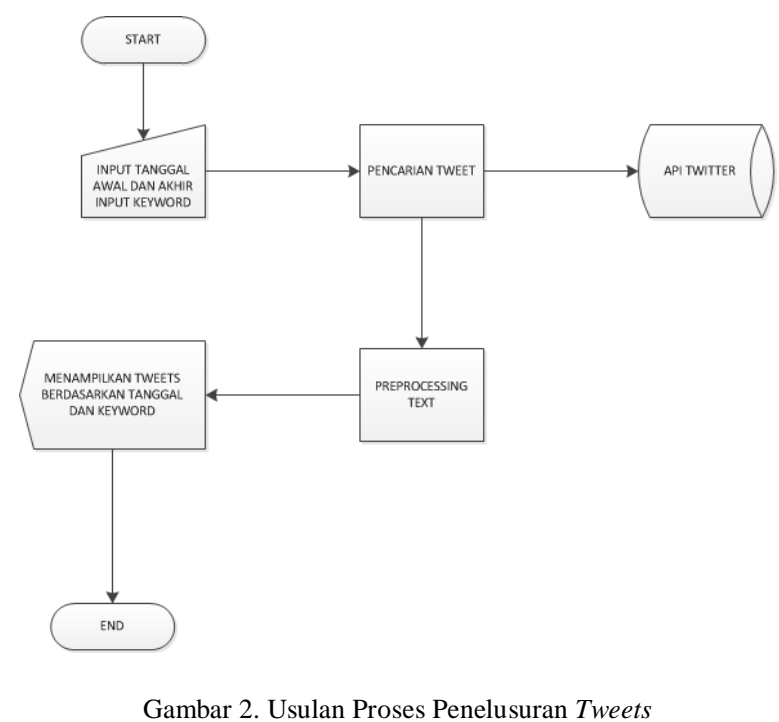

Berdasarkan Gambar 2, maka dapat dideskripsikan bahwa tahap-tahap pada proses penelusuran tweets pada aplikasi ini yaitu. 
1. User menginputkan tanggal awal dan akhir dan keyword sesuai yang diinginkan user.

2. Sistem akan melakukan proses pencarian tweets dengan cara mengambil tweets dari API Twitter.

3. Menggunakan twitteroauth agar dizinkan mengambil data dari API Twitter berupa data start_date, end_date dan q.

4. Data akan diproses melalui tahap preprocessing tweet yaitu proses memecah data tweets menjadi kata per kata dan diubah menjadi huruf kecil

5. Data yang diinginkan user akan di tampilkan kedalam bentuk web.

\section{Diagram Alur Preprocessing}

Pada penelitian ini, untuk proses penyaringan tweets menggunakan metode pre-processing text mining. Diagram alur untuk proses pre-processing dapat dilihat pada Gambar 3.

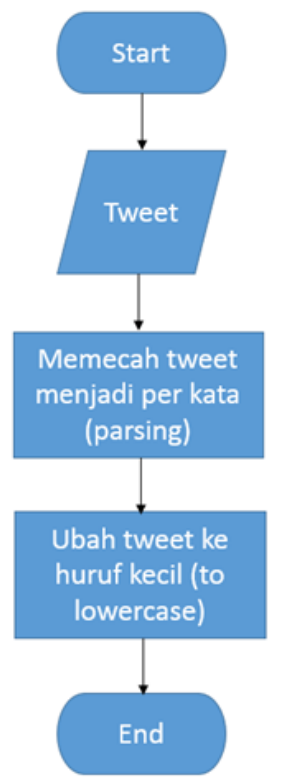

Gambar 3. Proses Pre-Processing Text

Berdasarkan Gambar 3, maka dapat dideskripsikan bahwa tahap-tahap pada preprocessing pada aplikasi ini yaitu.

1. Data berupa tweets yang telah didapatkan sebelumnya dari database akan melalui tahap parsing atau tiap tweets akan dipecah kedalam satu suku kata.

2. Tweets yang telah dipecah menjadi kata tunggal (unigram) akan melewati tahap lowercase atau diubah menjadi huruf kecil. Hal ini dilakukan karena untuk memudahkan tahap selanjutnya.

3. Setelah melewati proses diatas, aplikasi akan menampilkan hasil berupa tweets terurut berdasarkan kata kunci dan tanggal.

\section{Implementasi Sistem}

Berikut ini merupakan implementasi antarmuka user dari aplikasi yang dibangun.

1. Tampilan halaman untuk proses memasukkan keyword pencarian dapat dilihat pada Gambar 4.

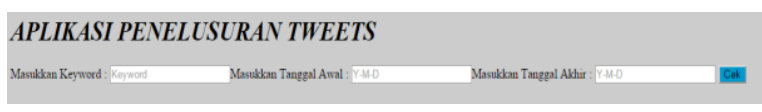

Gambar 4. Proses Input Keyword

Pada proses ini user akan menginputkan keyword lalu keyword tersebut di parsing ke API Twitter melalui nilai q. Twitter akan memberikan data keyword yang diminta melalui nilai q yang diinputkan di php.

2. Tampilan halaman untuk proses memasukkan tanggal dapat dilihat pada Gambar 5.

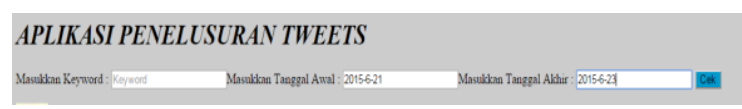

Gambar 5. Proses Input Tanggal

Pada proses ini user akan menginputkan tanggal awal dan tanggal akhir. Aplikasi akan meminta data dari API twitter melalui nilai "Since" dan "Until". API twitter akan memberikan data "Since" dan "Until" dengan syarat rentang waktu tidak lebih dari 9 hari dari tanggal saat menggunakan aplikasi.

3. Tampilan data hasil penelusuran tweets dan proses preprocessing dapat dilihat pada Gambar 6.

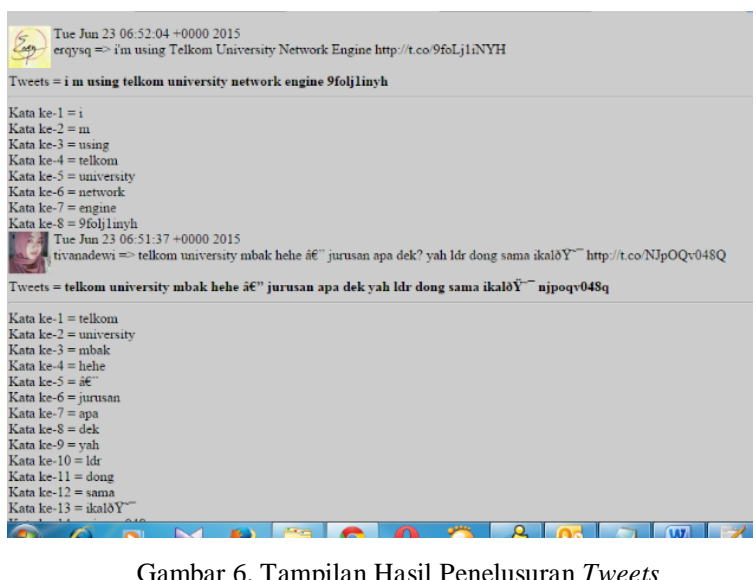

Pada proses ini akan ditampilkan tweets yang sesuai dengan yang diinputkan user. Data yang diambil berdasarkan data "Since","Until" dan " q" dari API twitter.

\section{E. Pengujian Sistem}

Hasil pengujian dari aplikasi pada penelitian ini dapat dilihat pada Tabel 3. 
Tabel 3. Black Box Testing

\begin{tabular}{|c|c|c|c|c|}
\hline $\begin{array}{l}\text { Nama } \\
\text { Field }\end{array}$ & Tipe Masukan & Output yang diharapkan & Output & Kesimpulan \\
\hline \multirow[t]{2}{*}{ Keyword } & $\begin{array}{l}\text { Keyword yang } \\
\text { diinginkan } \text { user }\end{array}$ & $\begin{array}{l}\text { Menampilkan tweets sesuai dengan } \\
\text { keyword yang diinputkan } \text { user }\end{array}$ & $\begin{array}{l}\text { Menampilkan tweets sesuai dengan } \\
\text { keyword yang diinputkan } \text { user }\end{array}$ & $\mathrm{OK}$ \\
\hline & Kosong & $\begin{array}{l}\text { Menampilkan tweets sesuai dengan } \\
\text { tanggal akhir }\end{array}$ & $\begin{array}{l}\text { Menampilkan tweets sesuai dengan } \\
\text { tanggal akhir }\end{array}$ & $\mathrm{OK}$ \\
\hline $\begin{array}{l}\text { Start } \\
\text { Date }\end{array}$ & $\begin{array}{l}\text { Tanggal yang } \\
\text { diinginkan } \text { user, } \\
\text { dengan format } \\
\text { YYYY-MM-DD }\end{array}$ & $\begin{array}{l}\text { Menampilkan tanggal dengan sesuai } \\
\text { dengan pilihan } u s e r\end{array}$ & $\begin{array}{l}\text { Menampilkan tanggal dengan sesuai } \\
\text { dengan pilihan } u s e r\end{array}$ & $\mathrm{OK}$ \\
\hline \multirow[b]{2}{*}{$\begin{array}{l}\text { End } \\
\text { Date }\end{array}$} & Kosong & $\begin{array}{l}\text { Menampilkan tweets sesuai dengan } \\
\text { tanggal awal }\end{array}$ & $\begin{array}{l}\text { Menampilkan tweets sesuai dengan } \\
\text { tanggal awal }\end{array}$ & $\mathrm{OK}$ \\
\hline & $\begin{array}{l}\text { Tanggal yang } \\
\text { diinginkan } \text { user, } \\
\text { dengan format } \\
\text { YYYY-MM-DD }\end{array}$ & $\begin{array}{l}\text { Menampilkan tanggal dengan sesuai } \\
\text { dengan pilihan } \text { user }\end{array}$ & $\begin{array}{l}\text { Menampilkan tanggal dengan sesuai } \\
\text { dengan pilihan } \text { user }\end{array}$ & $\mathrm{OK}$ \\
\hline Start & Kosong & $\begin{array}{l}\text { Menampilkan tweets sampai dengan } \\
\text { tanggal hari ini }\end{array}$ & $\begin{array}{l}\text { Menampilkan tweets sampai dengan } \\
\text { tanggal hari ini }\end{array}$ & $\mathrm{OK}$ \\
\hline $\begin{array}{c}\& \\
\text { End Date }\end{array}$ & $\begin{array}{l}\text { Tanggal yang } \\
\text { diinginkan } \text { user, } \\
\text { dengan format } \\
\text { YYYY-MM-DD }\end{array}$ & $\begin{array}{l}\text { Menampilkan tanggal dengan sesuai } \\
\text { dengan pilihan } \text { user }\end{array}$ & $\begin{array}{l}\text { Menampilkan tanggal dengan sesuai } \\
\text { dengan pilihan } \text { user }\end{array}$ & $\mathrm{OK}$ \\
\hline $\begin{array}{l}\text { Submit } \\
\text { data }\end{array}$ & - & $\begin{array}{l}\text { Menampilkan tweets berdasarkan } \\
\text { kriteria filter yang dibuat }\end{array}$ & $\begin{array}{l}\text { Menampilkan tweets berdasarkan } \\
\text { kriteria filter yang dibuat }\end{array}$ & $\mathrm{OK}$ \\
\hline
\end{tabular}

\section{F. Simulasi Kerja Aplikasi}

Hasil simulasi kerja pada aplikasi yang telah dibangun adalah seperti berikut.

1. Menginputkan keyword dan tanggal

Hasil simulasi contoh user menginputkan keyword "Telkom University" dan tanggal awal dan akhir 2015-6-23. Maka Aplikasi akan menampilkan tweets yang berkaitan tentang "Telkom University" di tanggal tersebut dapat dilihat pada Gambar 7-10.

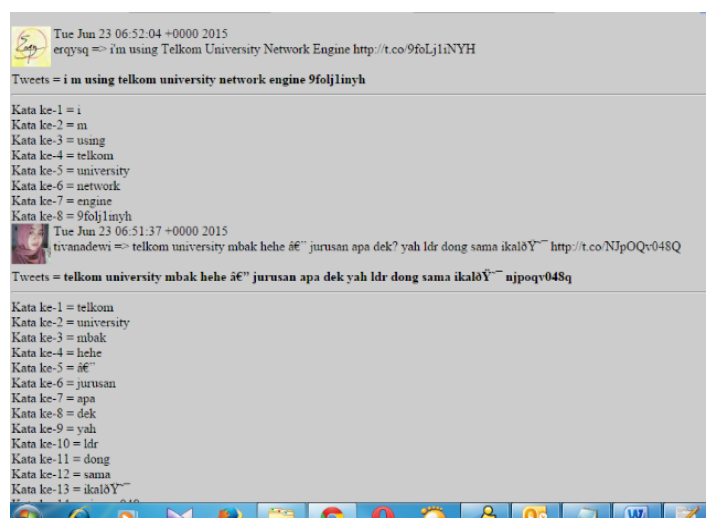

Gambar 7. Tampilan Data Bagian 1

Gambar 7 menunjukkan dua tweets dengan posisi pertama dan kedua dari atas tampilan aplikasi beserta hasil pre-processing nya. Semakin atas posisi menunjukkan keterbaruan dalam hal waktu.

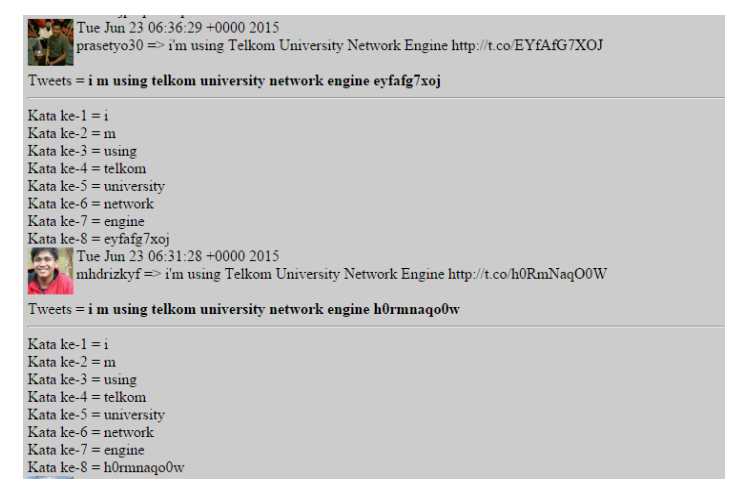

Gambar 8. Tampilan Data Bagian 2

Gambar 8 menunjukkan dua tweets dengan posisi ketiga dan keempat dari atas tampilan aplikasi beserta hasil pre-processing nya.

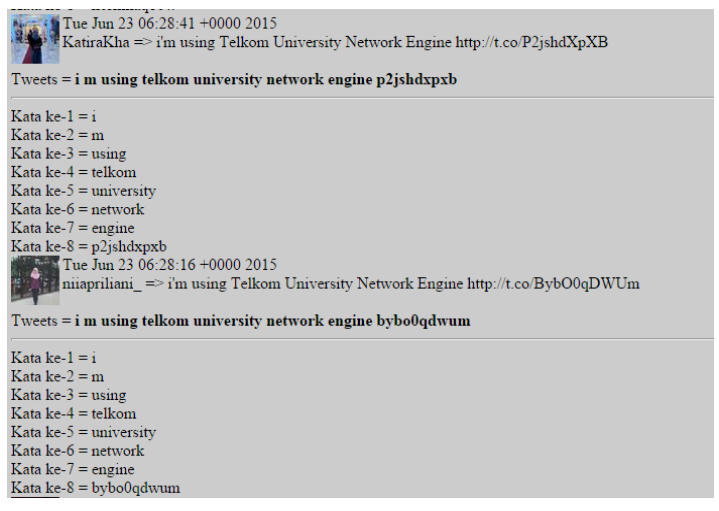

Gambar 9. Tampilan Data Bagian 3 
Gambar 9 menunjukkan dua tweets dengan posisi kelima dan keenam dari atas tampilan aplikasi beserta hasil pre-processing nya.

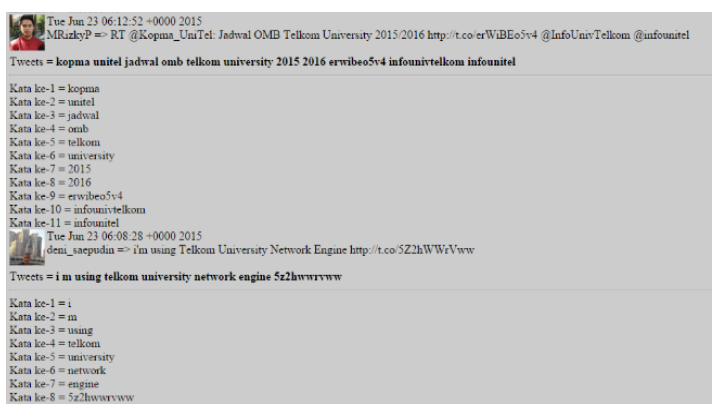

Gambar 10. Tampilan Data Bagian 4

Gambar 10 menunjukkan dua tweets dengan posisi ketujuh dan kedelapan dari atas tampilan aplikasi beserta hasil pre-processing nya.

\section{Menginputkan Tanggal Kosng}

Hasil simulasi contoh user tidak menginputkan tanggal dapat dilihat pada Gambar 11.

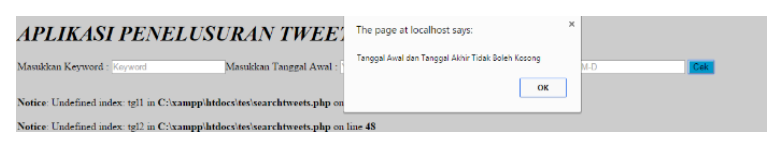

Gambar 11. Proses Input Tanggal Kosong

Pada proses ini, jika user tidak menginputkan tanggal awal dan tanggal akhir maka aplikasi akan memberikan notifikasi bahwa tanggal awal dan tanggal akhir tidak boleh kosong.

3. Menginputkan tanggal akhir

Hasil contoh simulasi jika user menginputkan tanggal akhir 2015-6-23 tanpa menginput tanggal awal dapat dilihat pada Gambar 12.

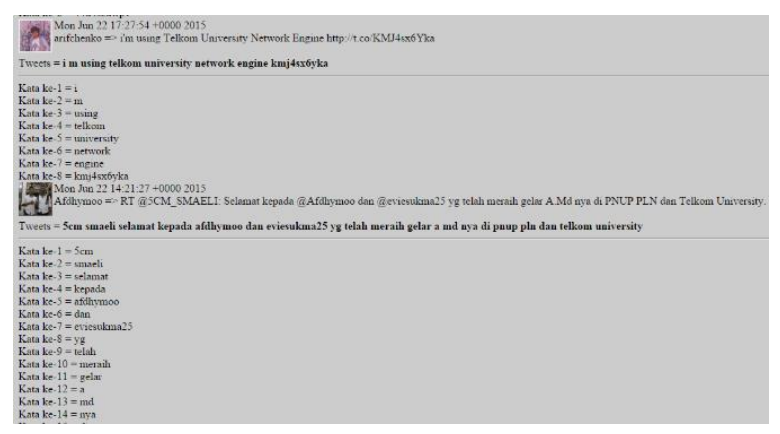

Gambar 12. Hasil Simulasi Tanggal Awal Kosong

Gambar 12 menampilkan data tweets dari 9 hari yang lalu sampai tanggal 2015-6-23.

4. Menginputkan Tanggal awal

Hasil simulasi jika user menginputkan tanggal awal 2015-6-22 tanpa menginputkan tanggal akhir dapat dilihat pada Gambar 13.

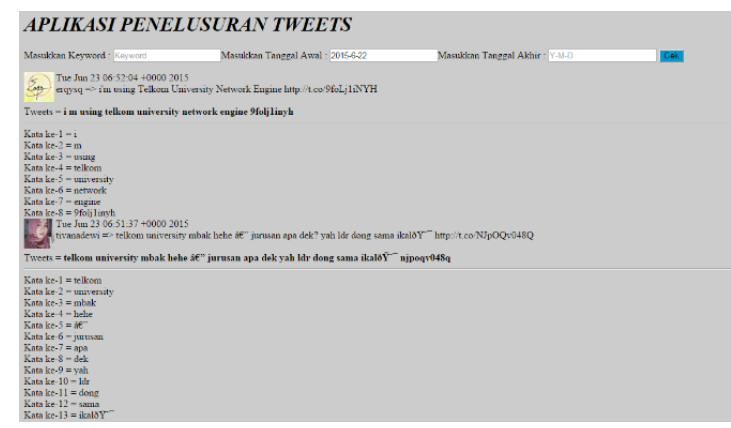

Gambar 13. Hasil Simulasi Tanggal Akhir Kosong

Gambar 13 menampilkan data tweets dari tanggal 2015-6-22 sampai hari ini.

5. Menginputkan tanggal awal lebih besar dari tanggal akhir.

Hasil simulasi jika tanggal awal diinputkan 2015-6-23 dan tanggal akhir diinputkan 20156-21 dapat dilihat pada Gambar 14.

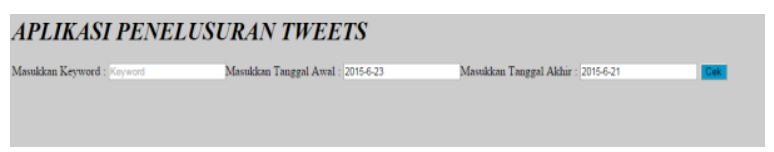

Gambar 14. Contoh Tanggal Awal Lebih Besar

Gambar 14 menunjukkan bahwa jika tanggal awal lebih besar dari tanggal akhir maka aplikasi tidak menampilkan hasil pencarian.

\section{PENUTUP}

Kesimpulan dari penelitian ini adalah penggunaan web crawler pada aplikasi yang dapat membantu menghimpun data tweets dan membantu mempersiapkan data untuk diolah menjadi informasi telah berhasil dilakukan berdasarkan analisa dan perancangan yang telah dilakukan. Hasil tweets yang dihimpun berdasarkan kata kunci dan tanggal pencarian telah dapat direpresentasikan kembali kedalam bentuk web berupa data-data hasil proses pre-processing. Penelitian ini masih banyak keterbatasan, sehingga perlu dilakukan beberapa pengembangan lebih lanjut terutama dalam hal kapasitas penyimpanan aplikasi dan juga dalah hal tingkat akurasi dari proses pre-processing.

\section{DAFTAR PUSTAKA}

[1] A.S, Rosa and Shalahudin, M. 2011. Modul Pembelajaran Rekayasa Perangkat Lunak (Terstruktur dan Berorientasi Objek). Modula, Bandung.

[2] Castillo, C. 2004. EffectiveWeb Crawling. (p. i). Dept. of Science: University of Chile

[3] Feldman, R \& Snager, J. 2007. The Text Mining Handbook: Advanced Approaches in Analyzing Unstructured Data. Cambridge University Press, New York

[4] Khanna, Rajiv A dan Kasliwal, Sourabh. 2007. Designing A Web Crawler. 
[5] Nur, Muhamad Yunus., \& Santika, Diaz. D. (2011). Analisis Sentimen pada Dokumen Berbahasa Indonesia dengan Pendekatan Support Vector Machine. Konferensi Nasional Sistem dan Informatika, (Vol. 009). Bali.

[6] Pitria, Pipit. 2014. Analisis Sentimen Pengguna Twitter Pada Akun Resmi Samsung Indonesia Dengan Menggunakan Naïve Bayes. Hyperlink: http://elib.unikom.ac.id/index.php/gdl.php?mod=brows e\&op=read\&id=jbptunikompp-gdl-pipitpitri-35651 diakses 7 April 2015.

[7] Pressman, S. Roger. 2010. Software Engineering: A Practitioner's Approach.

[8] Rosmala, Dewi \& Syafei, Rizqia Riyani. 2011. Implementasi Webcrawler pada Social Media
Monitoring. Hyperlink: http://lib.itenas.ac.id/kti/wpcontent/uploads/2013/10/No.-2-Vol.-2-Mei-Agustus2011-5.pdf diakses 7 april 2015.

[9] Sigit, Yohanes \& dkk. 2012. Analisis dan Perancangan Alat Bantu Monitor Brand Universitas Atma Jaya Yogyakarta di Situs Jejaring Sosial Twitter. Hyperlink:

http://jurnal.uajy.ac.id/jbi/2012/01/11/analisis-danperancangan-alat-bantu-monitor-brand-universitasatma-jaya-yogyakarta-di-situs-jejaring-sosial-twitter/ diakses 8 April 2015.

[10] Twitter. 2014. Tweets | Twitter Developers. Online. Hyperlink:https://dev.twitter.com/docs/platformobjects/tweets) diakses 6 April 2015. 
ISSN : 2085-3688; e-ISSN : 2460-0997

Penggunaan Web Crawler Untuk Menghimpun Tweets dengan Metode Pre-Processing Text Mining 